\title{
Feijão-de-porco e braquiária cultivados em sistema solteiro e consorciado
}

\author{
Franciele Caroline de Assis VALADÃO ${ }^{1}$, Daniel Dias VALADÃO JUNIOR*1, \\ Maíra RIZZI ${ }^{1}$, Marcionilio Caetano de SOUZA NETO ${ }^{1}$
}

\author{
${ }^{1}$ Instituto Federal de Educação, Ciência e Tecnologia de Mato Grosso, Campo Novo do Parecis, MT, Brasil. \\ (Orcid: 0000-0002-2046-3606; *; 0000-0003-4236-1093; 0000-0001-8860-8376) \\ *E-mail: daniel.valadao@cnp.ifmt.edu.br (Orcid: 0000-0001-6395-9778)
}

Recebido em 03/06/2020; Aceito em 14/09/2020; Publicado em 25/09/2020.

\begin{abstract}
RESUMO: Alguns fatores impedem que o Sistema de Plantio Direto (SPD) seja adotado em larga escala no Cerrado, dentro dos quais destacam-se a alta temperatura e alta pluviosidade característico do bioma que dificultam a manutenção da palhada sobre o solo e obtenção do verdadeiro SPD. O objetivo deste trabalho foi determinar o melhor arranjo entre feijão-de-porco (Canavalia ensiformis) e braquiária (Urochloa ruziziensis), quando cultivados com a finalidade de plantas de cobertura. O experimento foi implantado em Latossolo Vermelho de textura argilosa em blocos casualizados com quatro repetições e cinco tratamentos sendo: cultivo solteiro de braquiária; cultivo solteiro de feijão-de-porco; $25 \%$ de braquiária $+75 \%$ de feijão-de-porco; $50 \%$ de braquiária $+50 \%$ de feijão-de-porco; $75 \%$ de braquiária $+25 \%$ de feijão-de-porco. Avaliou-se a taxa de cobertura do solo, densidade de raiz, acúmulo de fitomassa, teor e acúmulo de nutrientes, decomposição, tempo de meia vida $\left(\mathrm{T}^{1 / 2}\right)$ e ciclagem de nutrientes pelas palhadas. Todos os tratamentos proporcionaram a taxa de $100 \%$ de cobertura. A relação N e C foi inversa nos tratamentos, sendo que os com maior presença de feijão-de-porco apresentaram maior teor de $\mathrm{N}$ e os com mais braquiária apresentaram maior teor C. O consórcio $50 \%$ braquiária $+50 \%$ feijão-de-porco se mostrou o arranjo mais favorável entre as duas espécies, visto que apresentou valores intermediários de taxa de cobertura, acúmulo e decomposição de massa seca e nutrientes, mantendo presente no sistema as características de ambas espécies.
\end{abstract}

Palavras-chave: Canavalia ensiformis; plantas de cobertura; sistema de plantio direto; Urochloa ruziziensis.

\section{Jack beans and brachiaria cultivated in a single and consortium system}

\begin{abstract}
Some factors prevent the No-Tillage System from being widely adopted in the Cerrado, among which the high temperature and high rainfall characteristic of the biome stand out, making it difficult to maintain the straw over the soil and obtain the true No-Tillage System. The objective of this work was to determine the best arrangement between jack beans (Canavalia ensiformis) and brachiaria (Urochloa ruziziensis), when cultivated with the purpose of cover crops. The experiment was carried out in a clayey Latossolo Vermelho in randomized blocks with four replications and five treatments: single brachiaria cultivation; single cultivation of jack beans; $25 \%$ brachiaria $+75 \%$ jack beans; $50 \%$ brachiaria $+50 \%$ jack beans; $75 \%$ brachiaria $+25 \%$ jack beans. The soil cover rate, root density, phytomass accumulation, nutrient content and accumulation, decomposition, half-life $\left(T^{1 / 2}\right)$ and nutrient cycling through straw were evaluated. All treatments provided a $100 \%$ coverage rate. The $\mathrm{N}$ and $\mathrm{C}$ ratio was inverse in the treatments, with those with a higher presence of jack beans having a higher $\mathrm{N}$ content and those with more brachiaria having a higher $\mathrm{C}$ level. The consortium $50 \%$ brachiaria $+50 \%$ jack beans proved to be the most favorable arrangement between the two species, since it presented intermediate values of coverage rate, accumulation and decomposition of dry mass and nutrients, keeping the characteristics of both species present in the system.
\end{abstract}

Keywords: Canavalia ensiformis; cover crops; no-tillage system; Urochloa ruziziensis.

\section{INTRODUÇÃO}

Na busca por aumentar a eficiência de produtividade, tem se adotado o sistema plantio direto (SPD). Um dos fatores imprescindíveis para o sucesso do mesmo é a implantação da cultura principal sob os restos culturais de uma cultura de cobertura que tenha sido introduzida em cultivo sequencial ou rotacionado (SILVA et al., 2017). Recentemente, as plantas de cobertura têm recebido expressiva atenção de pesquisas, pois constituem alternativas para elevar a sustentabilidade dos sistemas produtivos, sua rotação e consórcio podem ser adotadas juntamente com o SPD, estabelecendo-se, previamente, uma sequência de plantas de diferentes famílias. Como resultado, tem-se aumento nos quantitativos de resíduos deixados em superfície, o que contribui para a eficiência do modelo (VERONESE et al., 2012; ROSSI et al., 2013).

A vantagem da utilização de plantas de cobertura da família das leguminosas está no seu potencial de produção de biomassa e na sua capacidade de fornecer nitrogênio a cultura sucessora, porém essas plantas apresentam baixa relação $\mathrm{C} / \mathrm{N}$ e podem apresentar elevada taxa de decomposição de seus resíduos (TEIXEIRA et al., 2009). Em contrapartida, as gramíneas destacam-se por apresentarem alta produção de biomassa e de resíduos com relação $\mathrm{C} / \mathrm{N}$ alta, o que pode 
favorecer a redução na taxa de decomposição e a liberação mais lenta de nutrientes no solo (SILVA et al., 2012). Portanto, uma alternativa para reduzir os problemas com o monocultivo das plantas de cobertura é a adoção de consórcio de leguminosas e gramíneas, deixando uma relação $\mathrm{C} / \mathrm{N}$ intermediária, o que proporciona cobertura de solo e liberação de nutrientes de forma constante por um maior período de tempo, pois as leguminosas apresentam tempo de meia-vida $\left(\mathrm{T}^{1} / 2\right)$ menor que a de gramíneas (TEIXEIRA et al., 2009; SORAT'TO et al., 2012).

Neste sentido, objetivou-se recomendar para as condições do Cerrado um arranjo de consórcio entre feijãode-porco e braquiária mediante avaliação da taxa de cobertura, densidade de raiz, produção de fitomassa seca, relação $\mathrm{C} / \mathrm{N}$, o acúmulo de nitrogênio e carbono e a decomposição e liberação destes nutrientes das palhadas.

\section{MATERIAL E MÉTODOS}

O estudo foi realizado de março a dezembro de 2018 na área experimental do Instituto Federal de Educação, Ciência e Tecnologia de Mato Grosso, Campus Campo Novo do Parecis, em Latossolo Vermelho Distrófico típico, conforme princípios do Sistema Brasileiro de Classificação de Solos (SANTOS et al., 2018), cuja caracterização química de 0-0,20 $\mathrm{m}$ pelos métodos descritos por Teixeira et al. (2017) é de $\mathrm{pH}$ $\mathrm{H}_{2} \mathrm{O}: 6,22 ; \mathrm{pH}-\mathrm{CaCl}_{2}: 5,62 ; \mathrm{H}: 5,11 \mathrm{cmol}_{\mathrm{c}} \mathrm{dm}^{-3} ; \mathrm{Al}: 0,0 \mathrm{cmol}_{\mathrm{c}}$ $\mathrm{dm}^{-3}$; K: 35,78 $\mathrm{mg} \mathrm{dm}^{-3}$; P: 32,01 $\mathrm{mg} \mathrm{dm}^{-3}$; Ca: 2,67 $\mathrm{cmol}_{\mathrm{c}} \mathrm{dm}^{-}$ 3; $\mathrm{Mg}: 1,37 \mathrm{cmol}_{\mathrm{c}} \mathrm{dm}^{-3}$. A caracterização textural de $0-0,20 \mathrm{~m}$ é de $506 \mathrm{~g} \mathrm{~kg}^{-1}$ de argila; $134 \mathrm{~g} \mathrm{~kg}^{-1}$ de silte e $360 \mathrm{~g} \mathrm{~kg}^{-1}$ de areia. A área experimental, localiza-se a $13^{\circ} 40^{\prime} 31^{\prime \prime}$ de latitude Sul e 57 53'31" de longitude Oeste com $564 \mathrm{~m}$ de altitude. De acordo com os preceitos de Köppen, o clima da região é o tropical quente e úmido (Aw). As somas mensais de precipitações pluviais e temperaturas médias ocorridas durante o período experimental estão apresentadas na Figura 1.

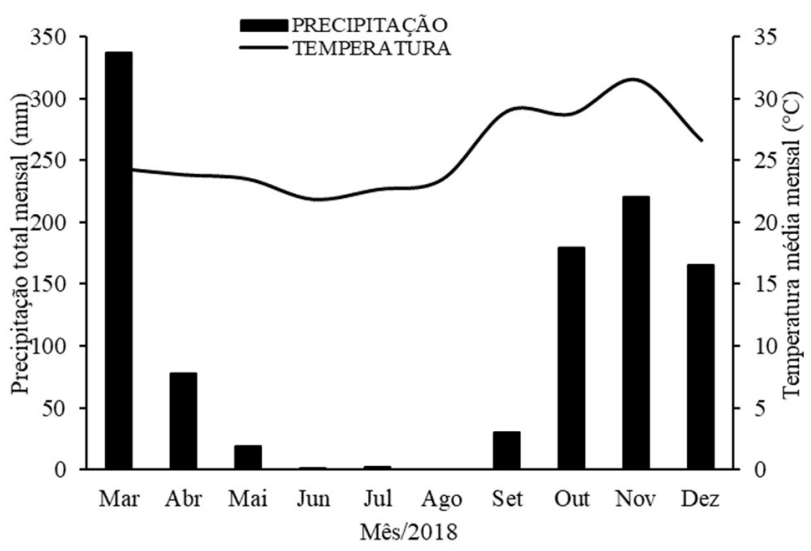

Figura 1. Precipitação $(\mathrm{mm})$ e Temperatura média do ar $\left({ }^{\circ} \mathrm{C}\right)$ mensais, para o período de março a dezembro na área experimental. Figure 1. Precipitation $(\mathrm{mm})$ and average air temperature $\left({ }^{\circ} \mathrm{C}\right)$ biweekly, for the period from march to december in the experimental area.

O delineamento experimental foi em blocos casualizados com cinco tratamentos e quatro repetições. Os tratamentos foram constituídos de arranjos de consórcios entre feijão-deporco (FP- Canavalia ensiformes) e braquiária (B- Urocholoa ruziziensis), sendo: T1- 100\% B; T2- 100\% FP; T3- 25\% B + $75 \%$ FP; T4- 50\% B + 50\% FP; T5-75\% B + 25\% FP.
As parcelas, medindo 4,5 x 5,0 m cada, foram demarcadas e posteriormente realizada a semeadura, sendo o feijão-deporco cultivado no sulco de semeadura espaçado de $0,45 \mathrm{~m}$ entre si e a braquiária semeada a lanço após a semeadura do feijão-de-porco. A braquiária teve densidade de semeadura de $20 \mathrm{~kg} \mathrm{ha}^{-1}$ e o feijão-de-porco com 5 sementes por metro linear. Para área útil foi descartado meio metro de cada extremidade da parcela.

Semanalmente após a semeadura, realizou-se as coletas de dados referentes a quantificação da taxa de cobertura com o auxílio de um quadrado de metal de $0,25 \mathrm{~m}^{2}$, uma vez por parcela, em ponto representativo da mesma, sendo a quantificação da taxa de cobertura feita por análise fotográfica em malha quadriculada de $33 \times 33$, totalizando 1089 quadrados.

As culturas foram mantidas até $70 \mathrm{DAE}$, momento em que $50 \%$ das plantas da segunda espécie a florescer (braquiária) apresentava-se em pleno florescimento. Nesse estádio, foi aberta uma trincheira por parcela de $0,45 \times 0,20$ $\mathrm{m}$ com a finalidade de avaliar a densidade e aspecto radicular nas camadas de 0,00 a $0,10 \mathrm{~m}$ e 0,10 a $0,20 \mathrm{~m}$. Para isso foi utilizado um quadrado de tamanho $0,20 \times 0,45 \mathrm{~m}$, marcado com malha de $0,05 \mathrm{~m}$. A avaliação foi realizada qualitativamente por meio de análise fotográfica. Após avaliação das raízes ocorreu a dessecação da área com uso de glifosato + óleo mineral, nas concentrações de $1440 \mathrm{~g}$ ia ha-1 $+0,5 \%$ de óleo mineral $\left(428 \mathrm{~g}\right.$ ia $\left.\mathrm{L}^{-1}\right)$, respectivamente.

$\mathrm{O}$ acúmulo de fitomassa foi obtido por meio da quantificação da massa seca da parte aérea (MSPA) das plantas de cobertura, sendo coletada a área útil. O material foi acondicionado em sacos de papel e seco em estufa de circulação de ar o à $65^{\circ} \mathrm{C}$, até atingir massa constante, na sequência os materiais foram pesados e seus valores estipulados para um hectare.

Com a massa seca obtida das plantas de cobertura, foi implantado o experimento para avaliação de decomposição e liberação de nitrogênio e carbono da palhada. Para esse experimento adotou-se o delineamento em blocos casualizados em esquema de parcela subdividida $5 \times 7$, onde $\mathrm{o}$ primeiro fator consistiu nos tratamentos de consórcios e o segundo fator em sete épocas de avaliação, sendo: $0,15,30$, 45, 60, 90 e 120 dias após a dessecação das plantas

As parcelas foram representadas por um litterbag de $0,2 \mathrm{x}$ $0,2 \mathrm{~m}$, confeccionado de tule com abertura de $2,0 \mathrm{~mm}$. Os litterbags foram preenchidos com a quantidade de palhada correspondente ao acumulado em cada tratamento por hectare, os quais, posteriormente, foram dispostos sobre o solo na área de origem da palhada.

Em cada uma das épocas predeterminadas, coletou-se um litterbag por parcela. $\mathrm{O}$ material foi lavado com detergente neutro e água deionizada, seco em estufa de ventilação forçada regulada a $65^{\circ} \mathrm{C}$ até obtenção de massa constante. Com esse resultado foi obtida a variável massa seca remanescente.

O material seco foi triturado em moinho tipo Wiley, passado em peneira de $0,5 \mathrm{~mm}$ e destinados as análises do teor e conteúdo de $\mathrm{N}$ e $\mathrm{C}$ conforme a metodologia de Teixeira et al. (2017). O teor de $\mathrm{N}$ foi obtido por digestão sulfúrica e destilação Kjeldahl e o teor de C por incineração em mufla. Os valores de conteúdo em $\mathrm{kg} \mathrm{ha}^{-1}$ foram obtidos sobre a quantidade de massa seca por hectare.

A massa seca decomposta em função do tempo foi calculada pela diferença entre o peso original e o peso determinado ao final de cada período de decomposição, 
obtendo-se assim, o percentual de massa seca remanescente. Com esses dados, estimou-se para cada parcela as taxas da decomposição e de liberação diária de nutrientes (k) utilizando o modelo exponencial simples (Equação 1), utilizado por Rezende et al. (1999), em que X é a massa seca ou nutriente remanescente após um período de tempo t, em dias; $\mathrm{X}_{0}$ é a massa seca ou nutriente inicial; e $\mathrm{k}$ é a constante de decomposição.

$$
x=x_{0} \cdot e^{-k}
$$

Reorganizando os termos da Equação 1, é possível calcular a constante de decomposição, ou valor k (Equação 2).

$$
k=\ln \left(\frac{x}{x_{0}}\right)^{/ \mathrm{t}}
$$

Com base também na decomposição da palhada foi calculado o tempo de meia vida, de acordo com Rezende et al. (1999) conforme equação 3, em que $T^{1 / 2}$ é o tempo de meiavida de massa seca ou nutriente; ln (2) é um valor constante; e k é a constante de decomposição descrita anteriormente.

$$
T^{\frac{1}{2}}=\frac{\ln (2)}{k}
$$

Os dados obtidos foram submetidos à análise de variância e quando $\mathrm{F}$ significativo $(\mathrm{p}<0,05$ ou $\mathrm{p}<0,01)$ foi aplicada análise de regressão para taxa de cobertura e para demais variáveis foi aplicado o teste de Tukey $(p<0,05)$. Para a determinação dos modelos relacionados às variáveis do estudo de decomposição foi utilizado o software CurveExpert.

\section{RESULTADOS}

Ao observar a evolução da taxa de cobertura de cada cultivo (Figura 2), verifica-se que os tratamentos solteiros de braquiária (Figura 2A) e feijão-de-porco (Figura 2B) atingiram $100 \%$ de cobertura do solo aos 31 e 35 DAE, respectivamente. Os demais cultivos, $25 \% \mathrm{~B}+75 \% \mathrm{FP}$ (Figura 2C), $50 \% \mathrm{~B}+50 \% \mathrm{FP}$ (Figura 2D) e $75 \% \mathrm{~B}+25 \% \mathrm{FP}$ (Figura 2E) atingiram $100 \%$ de cobertura do solo aos 35,34 e 33 DAE, respectivamente. O cultivo solteiro de braquiária e o cultivo de $75 \% \mathrm{~B}+25 \% \mathrm{FP}$, foram os que atingiram $100 \%$ de cobertura do solo em menor tempo após emergência.
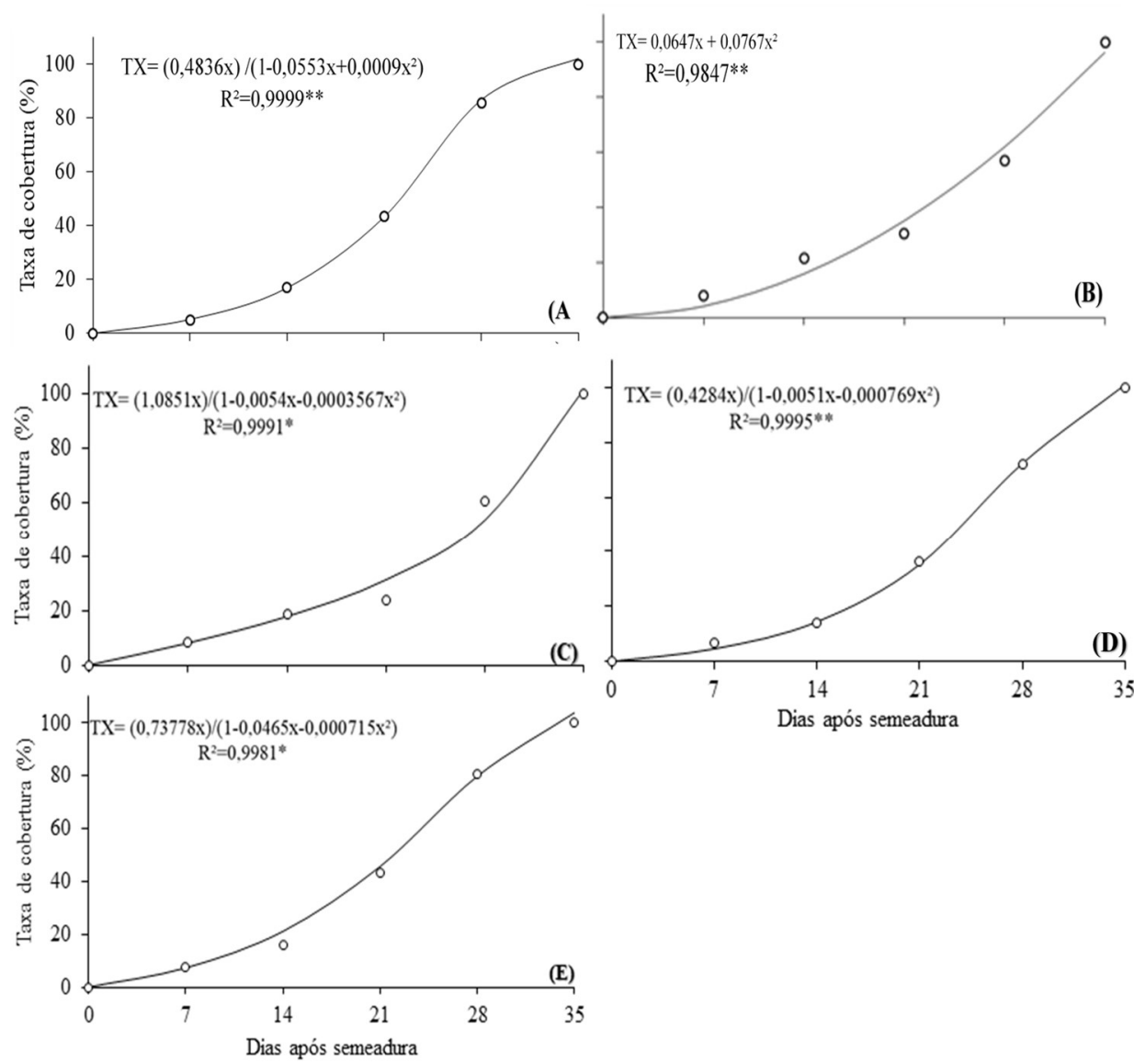

$\mathrm{TX}=(0,4284 \mathrm{x}) /\left(1-0,0051 \mathrm{x}-0,000769 \mathrm{x}^{2}\right)$ $\mathrm{R}^{2}=0,9995^{* *}$

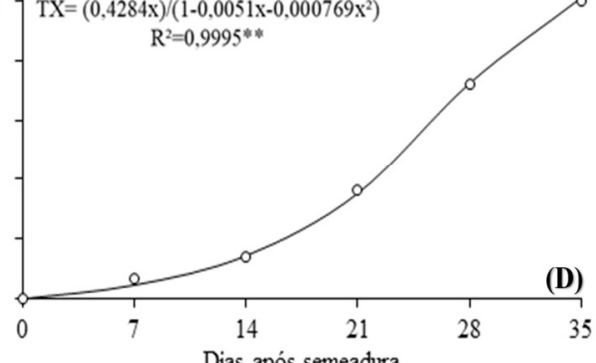

(D)

Figura 2. Evolução da taxa de cobertura no período de emergência até 35 DAE. A) cultivo solteiro B; B) cultivo solteiro FP; C) consórcio $25 \% \mathrm{~B}+75 \% \mathrm{FP}$; D) consórcio 50\% B + 50\% FP; E) consórcio 75\% B + 25\% FP.

Figure 2. Evolution of the coverage rate in the emergency period up to 35 DAE. A) B single crops; B) single FP cultivation; C) Consortium $25 \% \mathrm{~B}+75 \% \mathrm{FP}$; D) consortium 50\% B + 50\% FP; E) consortium 75\% B + 25\% FP.

$\mathrm{Na}$ Tabela 1 é possível observar a relação $\mathrm{C} / \mathrm{N}$ inicial e final de cada cultivo. O tratamento $100 \% \mathrm{~B}$ foi o que obteve o maior teor de $\mathrm{C} / \mathrm{N}$ inicial e final, seguido do arranjo $75 \% \mathrm{~B}+25 \% \mathrm{FP}$ com 18,24 inicial e 27,42 no final, Os arranjos com maiores proporções de feijão-de-porco obtiveram relação $\mathrm{C} / \mathrm{N}$ menores, tanto inicial quanto final. 
Tabela 1. Valor de relação $\mathrm{C} / \mathrm{N}$ inicial e final do material incubado na superfície do solo

Table 1. Initial and final $\mathrm{C} / \mathrm{N}$ ratio of the material incubated on the soil surface

\begin{tabular}{lcc}
\hline Arranjos & $\mathrm{C} / \mathrm{N}$ inicial & $\mathrm{C} / \mathrm{N}$ final \\
\hline $100 \% \mathrm{~B}$. & $21,9 \mathrm{a}$ & $36,0 \mathrm{a}$ \\
$100 \%$ FP. & $10,4 \mathrm{~d}$ & $18,5 \mathrm{~b}$ \\
$25 \% \mathrm{~B} .+75 \% \mathrm{FP}$. & $13,4 \mathrm{~cd}$ & $24,3 \mathrm{ab}$ \\
$50 \% \mathrm{~B} .+50 \% \mathrm{FP}$. & $15,5 \mathrm{bc}$ & $27,3 \mathrm{ab}$ \\
$75 \% \mathrm{~B} .+25 \% \mathrm{FP}$. & $18,2 \mathrm{ab}$ & $27,4 \mathrm{ab}$ \\
$\mathrm{CV}$ & 13,0 & 24,7 \\
DMS & 4,67 & 14,87 \\
\hline *Médias seguidas por mesma letra na coluna não diferem entre si pelo teste \\
Tukey (p<0,05). B=Braquiária ruzizienses; FP=Feijão-de-porco. CV: \\
coeficiente de variação (\%); DMS: diferença mínima significativa.
\end{tabular}

A maior taxa de liberação diária (k) de MSPA foi obtida no cultivo de feijão-de-porco solteiro, em contrapartida, quanto maior a proporção de braquiária no arranjo menor foi a liberação diária (Tabela 2). Em relação $\mathrm{T}^{1 / 2}$ para decomposição dos resíduos, observou-se que a metade dos resíduos derivados dos tratamentos $100 \% \mathrm{~B}$ e $75 \% \mathrm{~B}+25 \% \mathrm{FP}$, haviam se decomposto aos 77 dias e aos 66 dias, respectivamente. Os consórcios 25\% B+75\%FP e $50 \% \mathrm{~B}+50 \% \mathrm{FP}$ tiveram tempo $\mathrm{T}^{1 / 2}$ próximos, sendo, 57 e 60 dias. O tratamento de $100 \%$ FP foi o que obteve o menor $\mathrm{T}^{1 / 2}$, sendo de 46 dias.
No que se refere aos teores de $\mathrm{N}$ e C (Tabela 2), o tratamento que obteve maior teor de $\mathrm{N}$ foi o de $100 \% \mathrm{FP}$ e o menor teor foi $100 \% \mathrm{~B}$. Já os consórcios obtiveram valores intermediários não diferindo entre si. No caso do $\mathrm{C}$ o tratamento $100 \% \mathrm{~B} \quad$ e $75 \% \quad \mathrm{~B}+25 \% \mathrm{FP}$ apresentaram isoladamente as maiores médias não diferindo, no entanto, dos outros dois sistemas consorciados.

Na Figura 2 é possível observar a distribuição do sistema radicular dos cultivos, verificando-se de forma qualitativa o maior volume de raízes no cultivo de braquiária solteira (Figura 2A) e menor volume no cultivo de feijão-de-porco (Figura 2B), resultado condizente com o acúmulo de massa seca da parte aérea. Os sistemas consorciados tiveram produção de raízes intermediárias.

Ao analisar de maneira mais detalhada é possível verificar a importância dos sistemas na exploração do solo e consequente na ciclagem de nutrientes. Nesse caso, destacase o consórcio com $25 \% \mathrm{~B}+75 \% \mathrm{FP}$ uma vez que é possível identificar a presença tanto das raízes de braquiária quanto as de feijão-de-porco, em contrapartida, tanto no sistema $50 \% \mathrm{~B}+50 \% \mathrm{FP}$ quanto no $75 \% \mathrm{~B}+25 \% \mathrm{FP}$ verifica-se supressão das raízes de feijão-de-porco e predominância das raízes de braquiária. Dessa forma, ao se almejar o benefício das raízes de feijão-de-porco no sistema, o consórcio que traria maior resultado seria o $25 \% \mathrm{~B}+75 \% \mathrm{FP}$.

Tabela 2. Teores iniciais $\left(\mathrm{X}_{0}\right)$, liberação diária $(\mathrm{k})$ e tempo de meia-vida $\left(\mathrm{T}^{1 / 2}\right)$ de massa seca da parte aérea (MSPA), nitrogênio (N) e carbono (C) do material incubado na superfície do solo

Table 2. Initial content $\left(\mathrm{X}_{0}\right)$, daily release $(\mathrm{k})$ and half-live $\left(\mathrm{T}^{1 / 2}\right)$ of dry mass of the aerial part (MSPA), nitrogen $(\mathrm{N})$ and carbon $(\mathrm{C})$ of the material incubated on the soil surface

\begin{tabular}{|c|c|c|c|c|c|}
\hline \multirow[t]{2}{*}{ Arranjos } & \multirow{2}{*}{ Variável } & $\mathrm{X}_{0}$ & $\mathrm{k}$ & $T^{1 / 2}$ & Teor \\
\hline & & $\mathrm{kg} \mathrm{ha}{ }^{-1}$ & $\mathrm{~kg} \mathrm{ha}^{-1} \mathrm{dia}^{-1}$ & Dias & $\mathrm{g} \mathrm{kg}^{-1}$ \\
\hline $100 \% \mathrm{~B}$ & \multirow{7}{*}{ MSPA } & $6.625 a$ & $0,0090 \mathrm{c}$ & $77,50 \mathrm{a}$ & - \\
\hline $100 \% \mathrm{FP}$ & & $4.593 b$ & $0,0150 \mathrm{a}$ & $46,31 c$ & - \\
\hline $25 \% \mathrm{~B}+75 \% \mathrm{FP}$ & & $5.156 a b$ & $0,0122 \mathrm{ab}$ & $57,01 \mathrm{bc}$ & - \\
\hline $50 \% \mathrm{~B}+50 \% \mathrm{FP}$ & & $5.750 \mathrm{ab}$ & $0,0116 \mathrm{bc}$ & $60,38 \mathrm{bc}$ & - \\
\hline $75 \% \mathrm{~B}+25 \% \mathrm{FP}$ & & $6.268 \mathrm{a}$ & $0,0105 \mathrm{bc}$ & $66,78 \mathrm{ab}$ & - \\
\hline $\mathrm{CV}$ & & 12,62 & 10,45 & 11,04 & \\
\hline DMS & & 1.615 & 0,0027 & 15,33 & \\
\hline $100 \% \mathrm{~B}$ & \multirow{7}{*}{$\mathrm{N}$} & $171,3 a$ & $0,0061 \mathrm{~b}$ & $122,9 \mathrm{a}$ & $25,89 \mathrm{c}$ \\
\hline $100 \% \mathrm{FP}$ & & $204,1 \mathrm{a}$ & $0,0106 \mathrm{a}$ & $65,76 \mathrm{~b}$ & $44,12 \mathrm{a}$ \\
\hline $25 \% \mathrm{~B}+75 \% \mathrm{FP}$ & & $205,7 \mathrm{a}$ & $0,0070 \mathrm{ab}$ & $104,5 \mathrm{ab}$ & $38,27 \mathrm{ab}$ \\
\hline $50 \% \mathrm{~B}+50 \% \mathrm{FP}$ & & $191,3 \mathrm{a}$ & 0,0066b & $114,1 \mathrm{ab}$ & $34,99 \mathrm{abc}$ \\
\hline $75 \% \mathrm{~B}+25 \% \mathrm{FP}$ & & $185,2 \mathrm{a}$ & $0,0062 b$ & $117,0 \mathrm{a}$ & $30,15 b c$ \\
\hline $\mathrm{CV}$ & & 32,56 & 23,94 & 21,34 & 14,66 \\
\hline DMS & & 140,6 & 0,0039 & 50,44 & 11,47 \\
\hline $100 \% \mathrm{~B}$ & \multirow{7}{*}{$\mathrm{C}$} & $3.746 \mathrm{a}$ & $0,0033 a$ & $210,3 a$ & $565,6 a$ \\
\hline $100 \% \mathrm{FP}$ & & $2.113 b$ & $0,0059 \mathrm{a}$ & $119,1 \mathrm{~b}$ & $459,3 \mathrm{~b}$ \\
\hline $25 \% \mathrm{~B}+75 \% \mathrm{FP}$ & & $2.587 \mathrm{ab}$ & $0,0058 \mathrm{a}$ & $139,5 \mathrm{ab}$ & $503,9 \mathrm{ab}$ \\
\hline $50 \% \mathrm{~B}+50 \% \mathrm{FP}$ & & $2.917 \mathrm{ab}$ & $0,0049 \mathrm{a}$ & $145,1 \mathrm{ab}$ & $530,0 \mathrm{ab}$ \\
\hline $75 \% \mathrm{~B}+25 \% \mathrm{FP}$ & & $3.405 \mathrm{ab}$ & $0,0042 \mathrm{a}$ & $170,5 \mathrm{ab}$ & $543,7 \mathrm{a}$ \\
\hline $\mathrm{CV}$ & & 20,45 & 26,19 & 23,66 & 7,15 \\
\hline DMS & & 1.362 & 0,0028 & 83,72 & 83,95 \\
\hline
\end{tabular}

*Médias seguidas por mesma letra não diferem entre si pelo teste Tukey $(\mathrm{p}<0,05)$. FP $=$ Feijão-de-porco; $\mathrm{B}=\mathrm{Braquiária}$. $\mathrm{T}^{1} / 2=$ tempo de meia-vida. $\mathrm{K}=$ liberação diária. $\mathrm{X}_{0}=$ conteúdo inicial. CV: coeficiente de variação (\%); DMS: diferença mínima significativa.

\section{DISCUSSÃO}

Ao analisar os resultados, pensando no sistema de plantio direto, focando nos beneficios e na perenidade é possivel observar que, no geral, os tratamentos foram capazes de cumprir os requisitos minimos necessários, como, taxa de cobertura, produção de biomassa, liberação de nutrientes, durabilidade de palhada e sistema radicular diversificado e abundante.

A alta taxa de cobertura do solo, obtida no feijão-deporco solteiro, pode ser atribuida a ramificação abundante e a arquitetura foliar planiforme, além, do crescimento acelerado $e$ as amplas folhas cotiledonares da espécie 
(CARVALHO et al., 2013). No geral, ao se comparar os resultados de cobertura do solo obtidos, eles são superiores aos de Carvalho et al. (2013), que mediram uma taxa de cobertura de $97 \%$ aos 60 DAE com $75 \%$ milheto $+25 \%$ feijão-de- porco. No mesmo trabalho, contatou-se $100 \%$ de cobertura com o tratamento $50 \%$ sorgo $+50 \%$ feijão-deporco, entretanto, para tal resultado, o espaçamento foi reduzido para $0,25 \mathrm{~m}$ entre linhas e um estande de 10 plantas $\mathrm{m}^{-}$. Assim, acredita-se que o espaçamento de $0,45 \mathrm{~m}$ entre linhas pode ter influenciado positivamente na taxa de cobertura do solo, induzindo $100 \%$ de cobertura do solo em pleno florescimento.

Os consórcios com braquiária melhoram a taxa de cobertura no solo em relação ao cultivo de feijão-de-porco. Todavia, é importante ressaltar que tanto os cultivos solteiros como os consorciados tiveram rápido fechamento sobre o solo, característica importante ao se tratar de plantas de cobertura, visto que isto favorece a supressão de plantas daninhas, além de segurar umidade do solo ajudando a microbiota do mesmo. Isso pode ter ocorrido por essas espécies apresentarem tolerância ao estresse hídrico, por ser perenes, além de alta produção de fitomassa, o que resultou na total cobertura do solo (PACHECO et al., 2008).

Em um cenário de mudança climática, o sistema de plantio direto com manutenção de resíduos de culturas no solo, além de contribuir para os teores de MOS, pode diminuir os efeitos de secas, bem como evitar perdas de solo por erosão devido a ocorrência de chuvas fortes mais frequentes (CHERUBIN et al., 2018). A manutenção de até
50\% (9,5 $\left.\mathrm{Mg} \mathrm{ha}^{-1}\right)$ de palhada de cana-de-açúcar sobre a superfície do solo promoveu melhor conservação de água no solo por $\mathrm{Mg}$ de palha adicionada e retardou em até 11 dias o alcance do armazenamento crítico de água no solo, em comparação ao solo sem cobertura de palha (ANJOS et al., 2017). A temperatura da superfície do solo na camada de semeadura pode ser reduzida de 5 a $10^{\circ} \mathrm{C}$ quando o solo é coberto com palha de milho (LAL, 2009) e $2^{\circ} \mathrm{C}$ quando coberto com palha de cana (MOITINHO et al., 2013). Estudos têm demonstrado os efeitos benéficos na manutenção de resíduos culturais no controle de algumas pragas do solo e doenças. Qi et al. (2015) relataram que alta concentração $\left(>0,12 \mathrm{~g} \mathrm{~mL}^{-1}\right)$ de compostos liberados durante a decomposição da palha de milho afeta negativamente a quantidade, número e peso de esclerócios de fungos Rizoctonia sp. e Bipolaris sp.

Observa-se com os resultados obtidos para MSPA e sua decomposição a importância do consórcio entre plantas de cobertura para melhorar a cobertura do solo. De forma geral, os sistemas consorciados tiveram taxas de decomposição intermediárias entre $100 \% \mathrm{~B}$ e $100 \% \mathrm{FP}$. O maior destaque é para o consórcio $75 \% \mathrm{~B}+25 \% \mathrm{FP}$ que não diferiu do $100 \% \mathrm{~B}$, porém, nesse sistema a baixa proporção do feijão-de-porco poderia não garantir os benefícios esperados da leguminosa, uma vez que a proporção é muito baixa em relação a gramínea. Mas, nota-se que o sistema $50 \% \mathrm{~B}+50 \% \mathrm{FP}$ atingiu valores próximos de MSPA, cobertura do solo e decomposição o que o torna mais atrativo quando se deseja manter os benefícios das duas espécies no sistema.
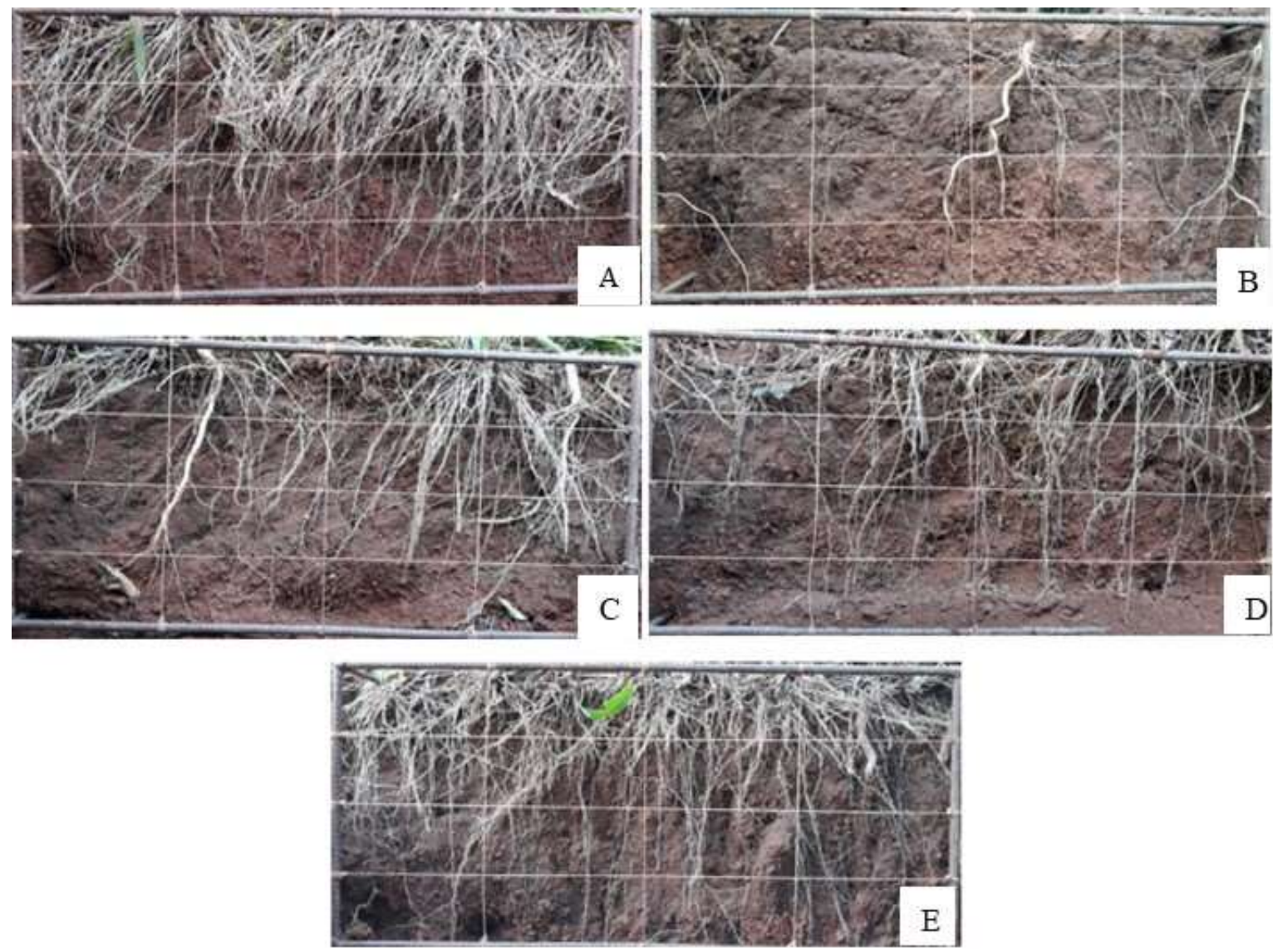

Figura 3. Distribuição de raízes das plantas de cobertura: cultivo solteiro de braquiária (A), cultivo solteiro de feijão-de-porco (B), 25\% $\mathrm{B}+75 \% \mathrm{FP}(\mathrm{C}), 50 \% \mathrm{~B}+50 \%$ FP (D), 25\% FP+75\% B (E). Campo Novo do Parecis, MT - 2018.

Figure 3. Root distribution of cover crops: single cultivation of brachiaria (A), single cultivation of jack beans (B), 25\% B + 75\% FP (C), 
$50 \% \mathrm{~B}+50 \% \mathrm{FP}(\mathrm{D}), 25 \% \mathrm{FP}+75 \% \mathrm{~B}(\mathrm{E})$.

Um aspecto importante da palhada, a qualidade, pode ser avaliada levando em cosideração a relação $\mathrm{C} / \mathrm{N}$, onde os maiores valores se relacionaram a maior presença da braquiária, isso pode estar relacionado a compostos resistentes a degradação (lignina, polifenóis, dentre outros). Dessa forma, o aumento no teor de $\mathrm{C}$ nos solos com cultivo de braquiarias pode estar ligado a qualidade do material orgânico a ser degradado do que a quantidade de material produzido, o que pode garantir maior permanência de $\mathrm{C}$ e menor permanência do N (COSTA et al., 2009). Pelo feijãode-porco possuir menor relação $\mathrm{C} / \mathrm{N}$ proporciona maior taxa de decomposição. Esses resultados evidenciam uma das vantagens de se utilizar plantas de cobertura da família das leguminosas a capacidade de fornecer $\mathrm{N}$ à cultura sucessora.

Uma alternativa para formação de palhadas com relação $\mathrm{C} / \mathrm{N}$ intermediária é fazer o consórcio de gramíneas e leguminosas, obtendo assim uma cobertura vegetal com taxa de decomposição mais lenta, mantendo o solo coberto por mais tempo e aumentando o teor de $\mathrm{N}$ no solo (FARINELLI; LEMOS, 2012). Os restos vegetais de plantas podem ser agrupados em duas classes: de decomposição lenta e de decomposição rápida, desta forma, restos culturais com relação $\mathrm{C} / \mathrm{N}$ menor que 25 , tem grande mineralização de $\mathrm{N}$ e rápida decomposição, diferente dos restos culturais com relação $\mathrm{C} / \mathrm{N}$ maior que 25 , que normalmente, apresentam forte imobilização de $\mathrm{N}$ e velocidade de decomposição lenta (FOLONI et al., 2016). Observa-se que os tratamentos solteiros e que possuem maiores proporções de feijão-deporco nos arranjos possuem relação $\mathrm{C} / \mathrm{N}$ menor de 25 , sendo considerados materiais vegetais de decomposição rápida, diferente dos que possuem maior proporções de braquiária, que possuem relação $\mathrm{C} / \mathrm{N}$ maiores de 25 , tornando-se assim materiais de decomposição lenta. Torres et al. (2014) encontraram resultados próximos em trabalho realizado na região de Uberaba-MG, onde o tempo meia vida encontrado para feijão-de- porco e braquiária foram de 52 e 70 dias, respectivamente. Esse padrão pode ser justificado pelo nitrogênio fixado pelas leguminosas, que favorecem positivamente a atividade dos microrganismos e proporcionam maiores velocidades de decomposição dos resíduos.

As gramíneas são desejáveis no consórcio quando se almeja formação de palhada no Cerrado brasileiro, pois mesmo em condições de altas temperaturas e umidades apresenta elevado $\mathrm{T}^{1} \frac{1}{2}$ o que permite que a palhada permaneça por um maior período sobre o solo, fornecendo proteção física, umidade e aumento dos teores de carbono orgânico no solo (ROSSI et al., 2013). De forma geral, práticas de manejo que melhoram a produção de massa seca das culturas e proporcionam uma diversificação de raízes no solo pode ser eficaz no aumento de MOS em longo prazo (GARCIA et al., 2013).

Quanto ao teor de nutrientes os resultados obtidos foram superiores aos encontrados por Pereira et al. (2017), que verificaram teores de $\mathrm{N}$ de 29,50 $\mathrm{g} \mathrm{kg}^{-1}$ na parte aérea de plantas de feijão-de-porco, cultivadas na safra de 2013/2014 no estado do Rio Grande do Sul. Bettiol et al. (2015) observaram resultados inferiores para teores de $\mathrm{N}$ em braquiárias, encontrando $10,60 \mathrm{~g} \mathrm{~kg}^{-1}$, no estado de Minas Gerais.

Outra característica importante, o crescimento radicular abundante pode auxiliar na melhoria das propriedades físicas do solo, notando-se menores valores de densidade do solo e maiores valores de macro porosidade em áreas de gramíneas, pois estas apresentam sistema radicular mais denso e distribuído, favorecendo maior agregação do solo, além disso, na decomposição das raízes, deixam galerias o que favorecem a oxigenação do solo (SILVA et al., 2017). Os beneficios de realizar cultivo com espécies de sistema radicular diferenciados, como a braquiária e o feijão-deporco, é a colaboração no crescimento de sistema radicular de culturas subsequentes as mesmas, agregação a estruturas do solo e acúmulo de matéria orgânica em profundidade. Tornando-se altamente relevante a utilização de plantas de cobertura nos sistemas de produção, podendo ser utilizadas em cultivo isolado ou consórcio entre ambas.

A alta concentração de raízes na camada superficial do solo supostamente contribui para baixos valores de resistência à penetração na referida camada (FERREIRA et al., 2018). Além da manutenção da qualidade do solo, Silva et al. (2019) verificaram um ganho de 232,5@ de carne, ou seja, 1,16@ de carne ha ${ }^{-1}$ em três meses, contribuindo para rentabilidade do produtor. Plantas de cobertura melhoraram as propriedades físicas do solo com aumento da macroporosidade e diminuição da microporosidade, isto é, é capaz de reduzir estados de compactação do solo (ASCARI et al., 2020). Alcoverde et al. (2020) avaliaram atributos físicos do solo e atributos produtivos da soja em Latossolo Vermelho sob SPD a 10 anos submetido a compactação por tráfego de trator e verificaram que apesar dos atributos físicos do solo apresentarem estados críticos para o desenvolvimento da cultura, não houve redução da produtividade de grãos, indicando que os teores de MOS obtidos no SPD tenham mantido as condições hídricas satisfatórias para o desempenho da cultura mesmo com resistência do solo superior a 2,0 Mpa.

\section{CONCLUSÕES}

O consórcio $50 \%$ braquiária $+50 \%$ feijão-de-porco se mostra como o arranjo mais favorável entre as duas espécies, visto que apresenta valores intermediários de taxa de cobertura, acúmulo e decomposição de massa seca e nutrientes, mantendo presente no sistema a características de ambas espécies.

\section{AGRADECIMENTOS}

Ao Instituto Federal de Mato Grosso (IFMT) e a Fundação de Amparo à Pesquisa de Mato Grosso (FAPEMAT) pelo apoio financeiro e concessão de bolsa de iniciação científica ao projeto.

\section{REFERÊNCIAS}

ALCOVERDE, S. N. S.; SOUZA, C. M. A.; RAFULL, L. Z. L.; CORTEZ, J. W.; ORLANDO, R. C. Soybean agronomic performance and soil physical attributes under tractor traffic intensities. Engenharia Agrícola, Jaboticabal, v. 40, n. 1, p. 113-120, 2020. DOI: http://dx.doi.org/10.1590/1809-4430-

Eng.Agric.v40n1p113-120/2020

ANJOS, J. C. R.; ANDRADE JÚNIOR, A. S.; BASTOS, E. A.; NOLETO, D. H.; MELO, F. B.; BRITO, R. R. Armazenamento de água em Plintossolo Argilúvico cultivado com cana-de-açúcar sob níveis de palhada. 
Pesquisa Agropecuária Brasileira, Brasília, v. 52, n. 6 , p. 464-473, 2017. DOI: https://doi.org/10.1590/s0100$204 \times 2017000600010$

ASCARI, J. P.; ARAÚJO, D. V.; MENDES, I. R. N.; PIETRO, R. S.; CARVALHO, M. A. C. Influence of biological fertilizer and plant cover in the physical properties of soil. Agrarian, Dourados, v. 13, n. 47, p. 42-55, 2020 .

DOI:

https://dx.doi.org/10.30612/agrarian.v13i48.7990

BETIOL, J. V. T.; PEDRINHO, A.; MERLOTI, L. F.; BOSSOLANI, J. W.; SÁ, M. E. de. Plantas de cobertura, utilizando Urochloa reziziensis solteira e em consórcio com leguminosas e seus efeitos sobre a produtividade de sementes de feijoeiro. Uniciências, Londrina, v. 19, n. 1, p. 3-10. 2015. DOI: https://doi.org/10.17921/1415$5141.2015 \mathrm{v} 19 \mathrm{n} 1 \mathrm{p} \% 25 \mathrm{p}$

CARDOSO, D. P.; CARVALHO, G. J.; SILVA, M. L. N.; FREITAS, D. A. F.; AVANZI, J. C. Atributos fitotécnicos de plantas de cobertura para a proteção do solo. Revista Verde de Agroecologia e Desenvolvimento Sustentável, Pombal, v. 8, n. 1, p. 1924, 2013.

CARVALHO, W. P.; CARVALHO, G. J.; ABBADE NETO, D. O.; TEIXEIRA, L. G. V. Desempenho agronômico de plantas de cobertura usadas na proteção do solo no período de pousio. Pesquisa Agropecuária Brasileira, Brasília, v. 48, n. 2, p. 157-166. 2013. DOI: 204X2013000200005

CHERUBIN, M. R.; OLIVEIRA, D. M. S.; FEIGL, B. J.; PIMENTEL, L. G.; LISBOA, I. P.; GMACH, M. R.; VARANDA, L. L.; MORAIS, M. C.; SATIRO, L. S.; POPIN, G. V.; PAIVA, S. R.; SANTOS, K. B.; VASCONCELOS, A. L. S.; MELO, P. L. A.; CERRI, C. E. P.; CERRI, C. C. Crop residue harvest for bioenergy production and its implications on soil functioning and plant growth: A review. Scientia Agricola, Piracicaba, v. 75 , n. 3, p. 255-272, 2018. DOI: https://doi.org/10.1590/1678-992x-2016-0459.

COSTA, O. V.; CANTARUTTI, R. B.; FONTES, L. E. F.; COSTA, L. M.; NACIF, P. G. S., FARIA, J. C. Estoque de carbono no solo sob pastagem em área de tabuleiro costeiro no sul da Bahia. Revista Brasileira de Ciência do Solo, Viçosa, v. 33, n. 5, p. 1137-1145, 2009. https://doi.org/10.1590/S0100-06832009000500007.

FARINELLI, R.; LEMOS, L. B. Nitrogênio em cobertura na cultura do milho em preparo convencional e plantio direto consolidados. Pesquisa Agropecuária Tropical, Goiânia, v. 42, n. 1, p. 63-70, 2012.

FERREIRA, C. J. B.; TORMENA, C. A.; CECATO, U.; FRANCO, H. H. S.; MOREIRA, W. H.; GALBEIRO, S.; RIBEIRO, O. L. Soil physical properties under a 'Tanzânia' grass pasture fertilized with mineral nitrogen or intercropped with stylosanthes. Pesquisa Agropecuária Brasileira, Brasília, v. 53, n. 4, p. 478-486, 2018. DOI: https://doi.org/10.1590/s0100204x2018000400009

FOLONI, J. S. S.; CATUCHI, T. A.; BARBOSA, A. M. de; CALONEGO, J. C.; TIRITAN, C. S. Acúmulo de nutrientes e relação $\mathrm{C} / \mathrm{N}$ em diferentes estágios fenológicos do milheto submetido a adubação nitrogenada. Revista Agro@mbiente On-line, Boa Vista, v. 10, n. 1, p. 1-9, 2016. DOI: http://dx.doi.org/10.18227/1982-8470ragro.v10i1.2798

GARCIA, R.A.; YUNCONG, L.; ROSOLEM, C.A. Soil Organic Matter and Physical Attributes Affected by Crop Rotation Under No-till. Soil Science Society of American Journal, v. 77, p. 1724-1731, 2013. DOI: https://doi.org/10.2136/sssaj2012.0310

LAL, R. Sequestering carbon in soils of arid ecosystems. Land Degradation and Development, v. 20, n. 4, p. 441-454, 2009. DOI: https://doi.org/10.1002/ldr.934

MALAVOLTA, E.; VITTI, G. C.; OLIVEIRA, S. A. Avaliação do estado nutricional das plantas: princípios e aplicações. 2. ed. - rev. e atual. Piracicaba: POTAFÓS, 1997. 319p

MOITINHO, M. R.; PADOVAN, M. P.; PANOSSO, A. R.; SCALA JÚNIOR, N. L. Efeito do preparo do solo e resíduo da colheita de cana-de-açúcar sobre a emissão de $\mathrm{CO}_{2}$. Revista Brasileira de Ciência do Solo, Viçosa, v. 37, n. 6, p. 1720-1728, 2013. DOI: https://doi.org/10.1590/S0100-06832013000600028.

PACHECO, L. P.; PIRES F. R.; MONTEIRO, F. P.; PROCÓCIO, S. O. de; ASSIS, R. L. de; CARMO, M. L. do; PETTER, F. A. Desempenho de plantas de cobertura em sobressemeadura na cultura da Soja. Pesquisa Agropecuária Brasileira, Brasília, v. 43, n. 7, p. 815-823, 2008. DOI: https://doi.org/10.1590/S0100204X2008000700005

PEREIRA, A. P.; SCHOFFEL A.; KOEFENDER J.; CAMERA J. N.; GOLLE D. P.; HORN R. C. Ciclagem de nutrientes por plantas de cobertura de verão. Revista de Ciências Agrárias, Lisboa, v. 40, n. 4, p. 799-807, 2017. DOI: http://dx.doi.org/10.19084/RCA17065

SILVA, A. G.; ASSIS, R. L.; OLIVEIRA, A. A.; FERREIRA, I. R. T.; ALMEIDA, K. L.; CARMO, E. L. Variabilidade dos atributos físicos do solo e dinâmica da palhada em sistema integração lavoura-pecuária no cerrado. Revista Brasileira de Milho e Sorgo, Sete Lagoas, v. 18, n. 3, p. 429-440, 2019. DOI: https://doi.org/10.18512/19806477/rbms.v18n3p429-440

REZENDE, C. P.; CANTARUTTI, R. B.; BRAGA, J. M.; GOMIDE, J. A.; PEREIRA, J. M.; FERREIRA, E.; TARRÉ, R.; MACEDO, R.; ALVEZ, B. J.; URQUIAGA，S.; CADISCH，G.; GILLER，K. E.; BODDEY, R. M. Litter deposition and disappearance in Brachiaria pastures in the Atlantic Forest region of the south of Bahia, Brazil. Nutrient Cycling in Agroecosystems, v. 54, n. 2, p. 99-112, 1999. DOI: https://doi.org/10.1023/A:1009797419216

ROSSI, C. Q.; PEREIRA, M. G.; GIÁCOMO, S. G.; BETTA, M.; POLIDORO, J. C. Decomposição de liberação de nutrientes da palhada de braquiária, sorgo e soja em áreas de plantio direto no Cerrado Goiano. Semina: Ciências Agrárias, Londrina, v. 34, n. 4, p. 1523-1534, 2013. DOI: https://doi.org/10.5433/16790359.2013v34n4p1523

SANTOS, H. G. dos; JACOMINE, P. K. T.; ANJOS, L. H. C. dos; OLIVEIRA, V. A. de; LUMBRERAS, J. F.; COELHO, M. R.; ALMEIDA, J. A. de; ARAUJO FILHO, J. C. de; OLIVEIRA, J. B. de; CUNHA, T. J. F. Sistema Brasileiro de Classificação de Solos. 5. ed., rev. e ampl. Brasília: Embrapa, 2018. 356p.

SILVA, M. P.; ARF, O.; SÁ, M. E. de; ABRANTES, F. L.; BERTI, C. L. F.; SOUZA, L. C. D. de. Plantas de cobertura e qualidade química e física de Latossolo 
Vermelho distrófico sob plantio direto. Revista Brasileira de Ciências Agrárias, Recife, v. 12, n. 1, p. 60-67, 2017.2 DOI: https://doi.org/10.5039/agraria.v12i1a5424

TEIXEIRA, C. M.; CARVALHO, G. J.; ANDRADE, M. J. B.; SILVA, C. A.; PEREIRA, J. M. Decomposição e liberação de nutrientes das palhadas de milheto e milheto + crotalaria no plantio direto do feijoeiro. Acta Scientiarum Agronomy, Maringá, v. 31, n. 4, p. 647653, 2009. DOI: https://doi.org/10.1590/S180786212009000400015.

TEIXEIRA, P. C.; DONAGEMMA, G. K.; FONTANA, A., TEIXEIRA, W. G. Manual de Métodos de Análise de Solo. 3 ed. ed., rev. e ampl. Brasília: Embrapa, 2017. 573p. TORRES, J. R. L.; SILVA, M. G. S. de; CUNHA, M. A. de; VALLE, D. X. P.; PEREIRA, M. G. Produção de fitomassa e decomposição de resíduos culturais de plantas de coberturas no cultivo da soja em sucessão. Revista Caatinga, Mossoró, v. 27, n. 3, p. 247-253, 2014. VERONESE, M.; FRANCISCO, E. A. B.; ZANCANARO, L.; ROSOLEM, C. A. Plantas de cobertura e calagem na implantação do sistema plantio direto. Pesquisa Agropecuária Brasileira, Brasília, v. 47, n. 8, p. 1158 1165, 2012. DOI: https://doi.org/10.1590/S0100204X2012000800017. 